Int. J. Dev. Biol. 60: 77-84 (2016)

doi: $10.1387 / \mathrm{ijdb} .160097 \mathrm{ag}$

\title{
Development vs. behavior: a role for neural adaptation in evolution?
}

\author{
ALAIN GHYSEN* and CHRISTINE DAMBLY-CHAUDIÈRE \\ Inserm, U1198, Montpellier, France; Université de Montpellier, Montpellier, France and EPHE, Paris, France
}

\begin{abstract}
We examine the evolution of sensory organ patterning in the lateral line system of fish. Based on recent studies of how this system develops in zebrafish, and on comparative analyses between zebrafish and tuna, we argue that the evolution of lateral line patterns is mostly determined by variations in the underlying developmental processes, independent of any selective pressure. Yet the development of major developmental innovations is so directly linked to their exploitation that it is hard not to think of them as selected for, i.e., adaptive. We propose that adaptation resides mostly in how the nervous system adjusts to new morphologies to make them functional, i.e., that species are neurally adapted to whatever morphology is provided to them by their own developmental program. We show that recent data on behavioral differences between cave forms (blind) and surface forms (eyed) of the mexican fish Astyanax fasciatus support this view, and we propose that this species might provide a unique opportunity to assess the nature of adaptation and of selection in animal evolution.
\end{abstract}

KEY WORDS: lateral line, plasticity, sensory system, Astyanax, Danio, Thunnus

\section{Developmental genetics and evolution}

A major question in accounting for evolution and speciation, is to understand how changes in patterns and forms are generated through mutation. This question has been much clarified over the past 30 years, with the advent of developmental genetics pioneered by Ed Lewis (1978), and it is now clear that the evolution of morphologies is a direct result of the evolution of development. As a result of this work, major aspects of morphological evolution can now be explained in terms of the underlying genetic changes. For example, the reason why some animals have two legs, while others have $4,6,8,10,100$ or 1,000 , has been largely clarified as being the result of changes in the function or expression of homeobox genes.

It is usually assumed that evolution is driven mostly by natural selection, i.e., selection of the fittest. But, is it more advantageous to have one pair of legs, or ten, or one hundred, or none? Clearly the question makes no sense, as we know of animals who thrive with each of those body plans. Yet all species appear by and large to have developed morphologies that are wonderfully adapted to their way of life, and each morphological novelty seems specifically tuned to subserve a distinct function, suggesting that natural selection has indeed been a major driving force in the evolution of forms. Here we explore the relation between evolution of pattern and evolution of function, based on the case of a sensory system specific to fish and amphibians, the mechanosensory lateral line system.

In most vertebrates, mechanosensory organs of various types are randomly distributed over the body surface, unlike in insects, where sensory bristles are often arranged in reproducible, species-specific patterns, facilitating the genetic analysis of pattern formation and pattern evolution (Simpson and Marcellini, 2006). In the lateral line system of fish, however, individual mechanosensory organs form specific patterns much as in invertebrates, allowing for a detailed analysis of pattern formation and evolution.

\section{Function and development of the lateral line system in fish}

The mechanosensory lateral line system functions as a distributed, local flow-sensitive device that allows the animal to perceive changes in its surrounding world, a sense that has been nick-named "touch-at-a-distance" (Dijkgraaf, 1963). It is implicated in many aspects of fish behavior such as prey detection, predator avoidance, schooling, rheotaxis, courtship, and many more, depending on the species (Montgomery et al., 1995).

\footnotetext{
*Address correspondence to: Alain Ghysen. cc105, Université de Montpellier, Place E. Bataillon, F-34095 Montpellier, France

E-mail: alain.ghysen@univ-montp2.fr
}

Accepted: 2 June 2016.

ISSN: Online 1696-3547, Print 0214-6282

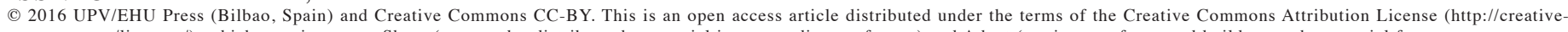

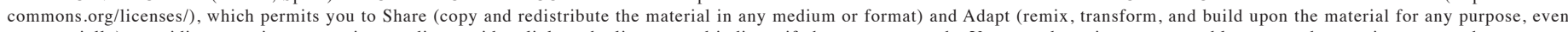

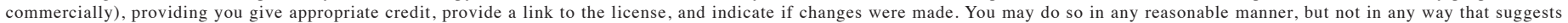
the licensor endorses you or your use. Printed in Spain 
The elementary unit of this system, the neuromast, comprises a core of mechanosensory cells very similar to the hair cells of the vertebrate inner ear, surrounded by various types of non-sensory support cells. Neuromasts develop during embryogenesis and throughout larval life to achieve their final pattern at the onset of adulthood (juvenile stage). They remain superficial throughout life, or sometimes become embedded in sub-epidermal canals. The neuromasts on the body (posterior lateral line, PLL) are arranged in patterns that vary widely across teleost species (Webb, 1989), although one frequent pattern is an arched line running along the side of the fish, dorsal to the horizontal myoseptum (Fig. 1).

The embryonic development of the PLLdepends on the formation of an embryonic primordium that moves all the way from the otic region to the posterior tip of the body, as first shown in amphibians by Harrison (1904) and Stone (1933). During its migration the primordium deposits groups of cells, the prospective neuromasts, in its wake. A similar process of long-range, collective cell migration also takes place in the zebrafish, Danio rerio (Metcalfe, 1989). The molecular bases of this process have been extensively studied over the last decade in the zebrafish Danio rerio (rev. in Ghysen and Dambly-Chaudière, 2007, Ma and Raible, 2009, Chitnis et al., 2012). The various developmental operations that mediate the larval development of the zebrafish PLL, from the embryonic pattern (one line of 7 neuromasts), to the juvenile pattern of four lines totaling about 50 neuromasts, have also been identified, although their molecular mechanisms are still largely unknown. Briefly, the transition from embryonic to juvenile patterns includes (1) the formation of additional primordia that also move along the antero-posterior axis during early larval life (Ledent, 2002, Sapède et al., 2002, Nuñez et al., 2009); (2) the migration of differentiated neuromasts along the dorso-ventral axis (Sapède et al., 2002), and (3) the formation of intercalary neuromasts in between the neuromasts deposited by the migrating primordia (Grant et al., 2005, Lopez-Schier and Hudspeth, 2005). Once the juvenile pattern is formed, a subset of superficial neuromasts may become embedded in sub-epidermal canals (Wada et al., 2014). A final step of amplification, whereby each superficial neuromast of the juvenile gives rise to a cluster of neuromasts, takes place during adult life (Ledent, 2002, Wada et al., 2013).

\section{Comparative analysis of lateral line development}

Previous analyses of lateral line evolution have concentrated on comparative descriptions of adult patterns, or more rarely of larval patterns (e.g., Webb, 1989, Northcutt, 1990). This approach revealed a large diversity of pattern variations, and was used to infer putative ancestral patterns. Its strictly descriptive nature,

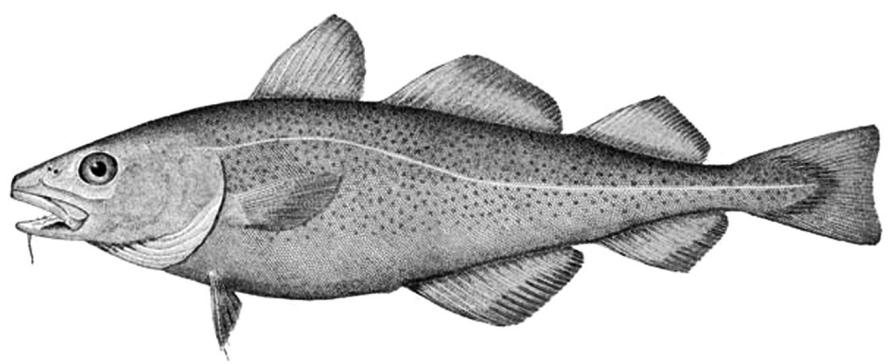

Fig. 1. Codfish. Drawing by H. L. Todd (Brown Goode, 1884).

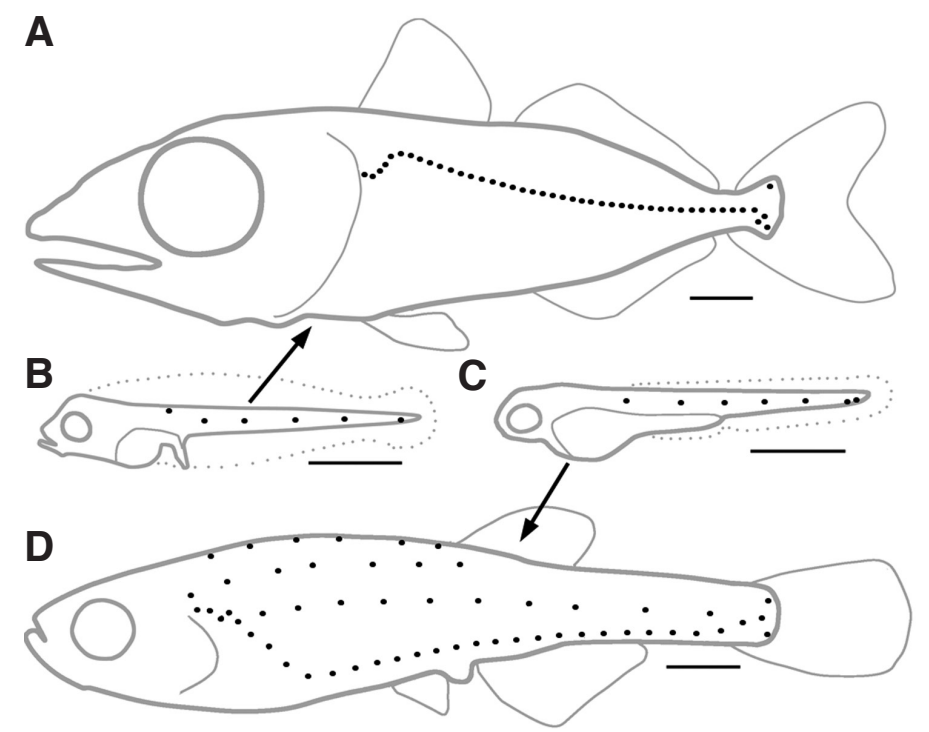

Fig. 2. The juvenile patterns of Thunnus thynnus (blue-fin tuna, A) and of Danio rerio (zebrafish, D) are derived from nearly identical embryonic patterns $\mathbf{( B , C )}$ respectively. Scale bars, $1 \mathrm{~mm}$.

however, could yield no information on the mechanisms whereby the underlying developmental processes changed or diversified during evolution, to generate such diverse patterns.

Our improved understanding of the generative mechanisms involved in Danio PLL development has made it possible to investigate the nature of the developmental changes that underly variations in the juvenile/adult pattern. A case in point is the very large difference between the juvenile pattern in the Atlantic bluefin tuna (Thunnus thynnus), which comprises a single arched line slightly dorsal to the horizontal myoseptum (Fig. 2A), and in the zebrafish with its four lines of neuromasts extending at various dorso-ventral levels (Fig. 2D). Danio and Thunnus belong respectively to the Ostariophysii and the Acanthopterygii superorders of teleost fishes, which diverged around 290 Myrs ago (Steinke et al., 2006, Hurley et al., 2007), and are therefore as distantly related as any two teleosts can be.

Even though the juvenile pattern of PLL in Thunnus is dramatically different from that in Danio, and in spite of the widely different environments they live in, the embryonic patterns are indistinguishable between the two species (Fig. 2B, C), and result from identical processes of cell migration and cell deposition (Ghysen et al., 2010). The developmental operations involved in the transformation of the embryonic into the juvenile pattern during larval life are also the same in Danio and in Thunnus, with only one noticeable exception: although in both species there is migration of differentiated neuromasts along the dorso-ventral axis, this migration happens to be ventralwards in Danio, but dorsalwards in Thunnus (Ghysen et al., 2012). This small difference has profound consequences on the further development of the system, as the presence of dorsally migrated neuromasts in Thunnus constrains the path of the secondary primordium, resulting in a single line of primary and secondary neuromasts, whereas in Danio, the ventral migration of early neuromasts generates a ventral line, coexisting with a new lateral line formed by the secondary primordium (Fig. 3).

A second small difference, extrinsic to PLL development, is the 
position of the dorsal fin. In both Danio and Thunnus, the dorsal primordium stops its migration at the anterior edge of the dorsal fin. Because this fin is duplicated in acanthopterygians (Mabee et al., 2002), the very anterior position of the anteriormost dorsal fin of Thunnus (Fig. 3) limits the extent of its dorsal line so drastically that this line had not been noticed so far. Altogether, these two differences, one intrinsic to PLL development and the other related to other aspects of larval development, are entirely sufficient to account for the huge difference between the juvenile patterns found in Danio and in Thunnus.

We conclude that the same developmental mechanisms - migration of the embryonic primordium, formation and migration of additional primordia, migration of differentiated neuromasts, and formation of intercalary neuromasts - are highly conserved between zebrafish and blue-fin tuna, although they end up producing very different morphologies. The formation of diverse adult PLL patterns appears, therefore, not to be the effect of diverse mechanisms, but of the diverse use of the same few developmental mechanisms. Based on the example of Danio and Thunnus, it seems easy to imagine how the same conserved mechanisms could possibly generate any PLL pattern (Ghysen et al., 2014). Needless to say, we have to know more about the molecular bases of these mechanisms to determine to what extent they have been truly conserved, and also, to pinpoint the origin of the small changes in their deployment that result in large differences in final patterns.

\section{Adaptation vs. exploration}

The finding that small differences acting during or shortly after embryogenesis may cause major changes in adult morphologies is of course not limited to the PLL, raising the question of whether there is any adaptive value in such changes, or whether they just reflect small differences in developmental processes, independent of any selective pressure. This question is notoriously difficult to answer, as it is not possible to rewind the entire process of speciation and examine it at leisure (Gould, 1989). Further, all species appear by and large to have developed morphologies that are wonderfully adapted to their way of life, suggesting that natural

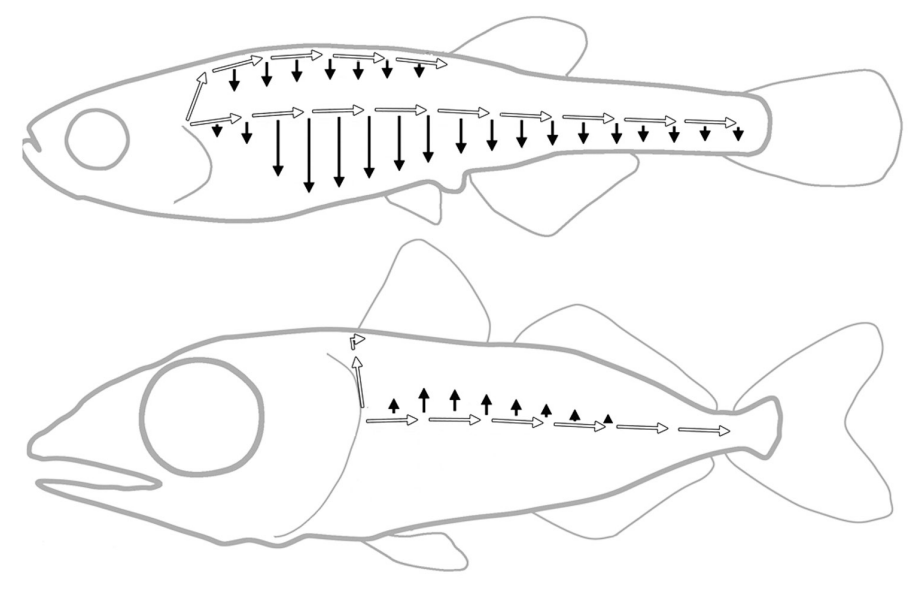

Fig. 3. Migration of lateral line primordia (white arrows) and of differentiated neuromasts (black arrows). Opposite directions of neuromast migration along the dorso-ventral axis, and varying positions of the dorsal fin, account for the difference between the four-lined pattern of the zebrafish, and the single line of tuna. selection has indeed been a major driving force in the evolution of morphologies.

The "Just so stories" of Kipling illustrate how easy it is to "explain" the peculiarities of animal shapes and patterns, the problem being, of course, that the relevance of such a posteriori explanations is very difficult to evaluate in any objective way (Gould and Lewontin, 1979). Hypotheses aimed at "explaining" this or that morphology as a response to some selective pressure are notoriously impossible to demonstrate, and the description of a possible "selective pressure" is often considered almost as valuable as the demonstration that it actually played a role in the process of speciation!

Looking at morphologies from the point of view of the underlying developmental processes suggests, however, an alternative framework. Developmental changes are unavoidable consequences of random mutation. Thus any species is bound to continuously explore variant morphologies. It has been convincingly argued that the molecular basis of morphological variation may most often arise through alterations in the control regions of specific genes, resulting in changes in their patterns of expression, and ultimately in changes in the deployment of downstream elements (Carroll et al., 2008). Although we do not know the molecular basis for the small difference between the PLL of Danio and Thunnus, it seems plausible that a change in signaling pathways downstream of neuromast differentiation genes may cause a reversal of the direction of movement through the epidermis, from ventralwards in Danio to dorsalwards in Thunnus.

The question, then, is to know whether this change is adaptive, i.e., a response to selective pressure, or exploratory, i.e. the result of unselected but unavoidable variation. We argue that adaptive explanations for the similarity between Danio and Thunnus embryos, and for the difference between the juvenile patterns, are difficult to envision, for two reasons that we will examine in turn in the following paragraphs.

\section{Adaptive patterns?}

Even though the embryonic PLL of Danio and of Thunnus are indistinguishable, the response to PLL stimulation differs completely between the two species. In Danio the stimulation of the PLL induces the so-called escape reaction: a C-turn followed by a forward acceleration of the body (Weihs, 1973). In tuna, PLL stimulation triggers a strike reaction: a forward movement accompanied by jaw opening (unpublished observations). In yet another species, the hunting archer fish, escape and strike reactions co-exist, and share a common network of pre-motor (reticulospinal) neurons (Wöhl and Schuster, 2007). Thus it appears that conserved motor modules may be differentially activated in different species, in response to similar stimuli, thereby mediating different behaviours. More generally, the conservation of PLL patterns in early larvae of different species living in different environments (Pichon and Ghysen, 2004), and reacting to its stimulation with different behavioral responses, suggests that the pattern of the embryonic PLL is dictated by the way it develops, rather than shaped by selective pressure.

As concerns the juvenile/adult pattern, the Thunnus pattern is common to fishes that live in the open ocean and to fishes that live in shallow freshwaters much as Danio does (Nelson, 1994), to predators as well as to plant-eaters, etc. This makes it unlikely that the dramatic difference in the environments and life styles of Danio and of Thunnus has played a major role in shaping their respective 
juvenile PLL patterns. Along the same line, at least one study on a monophyletic group of Antarctic fishes (Notothenoids) has led to the conclusion that "differences in lateral line structures, even large ones, do not necessarily have consequences for function" (Montgomery et al., 1994, 1995). If different PLL morphologies may underly similar behaviors, whereas common morphologies underly species-specific differences in behavior, then we can reasonably conclude that specific changes in PLL pattern may not be identifiably linked to specific selective pressures.

\section{Adaptation - to what?}

These observations suggest that there is no clear relationship between the patterning of sensory elements, and the way their information is handled to generate an "appropriate" response. Whereas the embryonic PLL pattern appears to be dictated by the way it develops, the behavioral response that it elicits seems rather adaptive, as the difference between the responses of $\mathrm{Da}$ nio and Thunnus early larvae corresponds well to the different conditions they encounter (Ghysen et al., 2014). The "escape" reaction of Danio may be very useful if lots of hiding places are at close reach, as in the shallow, slow-flowing, well-vegetated waters where zebrafish live (Engeszer et al., 2007, Spence et al., 2008). A similar escape response would possibly be not so useful in open water, because if the predator misses the first time because of an "escape reaction", it is very unlikely to miss a second time. On the other hand, the "strike" reaction of Thunnus may make all the difference for a larva that has to eat on its first day of larval life, because its yolk sac is exhausted on the next day, contrary to Danio larvae that do not need to eat before 3 or 4 days after hatching - a time when both species have developed a fully functional visual system. Obviously those are no more than plausible speculations, or "Kipling-esque" explanations, yet the fact is that identical PLL patterns trigger different, and appropriate, behavioral responses in early larvae of Danio and Thunnus.

Bearing in mind the appropriateness of behavioural differences between the two types of larvae, we propose that, in the case of the embryonic PLL, behavioral differences (motor outputs to lateral line inputs) reside in neural adaptations (how brain circuits utilize lateral line sensory information) rather than in morphological adaptations of the sensory pattern. Thus adaptation would reside mostly in neural adjustment to make the best use of sensory systems that are patterned, not by adaptive, but by developmental constraints. More generally, we propose that organisms neurally adapt to whatever tools they are provided with by their own development, and use them as best as they can, thereby giving the impression that such tools were actually selected for (Ghysen et al. 2014).

\section{Neural adaptation}

The concept of neural adaptation provides an interesting alternative to the usual view that variations of pattern and forms are necessarily adaptive, and were actually selected for. This hypothesis implies that selection may shape neural circuitry more easily than it does sensory patterns or morphologies. There may be good reasons for this prevalence of neural adaptation in evolution.

First, the nervous system is par excellence the organ that epitomizes plasticity. Synaptic plasticity, neuronal plasticity, and circuit plasticity, are intrinsic components of the workings of the nervous system. This prevalence of plasticity implies that the nervous system is remarkably able to respond to changes and to novelties. Plasticity is, by definition, a response of the individual to altered environmental conditions, but it seems likely that behavioral responses achieved through plastic rearrangement in one individual, can easily be implemented or reinforced genetically, and therefore become inheritable. Indeed the idea that plasticity-generated variation may become genetically fixed was proposed one century ago by Baldwin ("orthoplasy"), and updated as "genetic assimilation" by Waddington 70 years ago. This concept ("genetic accomodation", West-Eberhard, 2003) has become a major theme in discussions of the origin of evolutionary change (e.g., Crispo, 2007, Badyaev, 2009, Sznajder et al., 2012).

A second reason why the nervous system may be particularly amenable to "inheritable plasticity" is that the level of cell specification is much higher than in any other tissue. Neuronal cell type specification is a prevalent feature of the central nervous system, where it relies on at least three different sets of genes acting in a combinatorial way: antero-posterior specification through the homeotic genes, dorso-ventral specification through the action of ventralizing genes, and neuronal subtype specification through the bHLH genes. This 3-dimensional specification effectively isolates small subsets of neurons from each other and from the system at large, making it possible to introduce changes in each subset without disturbing the function of the other subsets, thereby facilitating the evolution of adaptive behaviors (Brunet and Ghysen, 1999).

The idea that neural adaptation may play an important role in evolution and speciation is, therefore, consistent with prominent features of the central nervous system. Neural adaptation could work in (at least) two ways: it could provide animals with different behavioral answers to similar sensory inputs, but it could also be the basis for the remarkable match between morphologies and functions, by fostering behavioral variations that make the best use of morphological novelties. The difficulty, however, is to go beyond the argument of plausibility, and to seek how the validity of this proposal could be experimentally tested.

Basically, the question amounts to defining the origin of changes in behavior that accompany the development of new morphologies, and to assess whether morphological changes have intrinsic adaptive value, or whether selection acts primarily on behavioral adaptation. How the central nervous system evolves to produce behavioral changes remains largely unknown, however: in contrast to physiology and morphology, our understanding of how behavior evolves is still limited to the effect of changes in the peripheral nervous system (Cande et al., 2013). Identifying both the underlying genetic changes, and the resultant physiological changes, that lead to behavioral divergence is obviously a daunting task. In spite of some progress made recently in this direction in the case of the courtship behavior of drosophilid flies, which shows marked changes between closely related species (Cande etal., 2012, 2014), we are still very far from a working knowledge of the genetics of behavioral traits, and even more so, of their evolution.

An additional problem in assessing the nature and direction of selection and adaptation is, obviously, the considerable length of these processes: the formation of new patterns and of new species takes place over periods on the order of millions of years, making it impractical to study such processes over one scientist's lifetime. We may, however, come back to the particular case of the lateral line system for a possible approach to the question of the relative 
importance of selection, of adaptation, and of morphological innovation, in speciation.

\section{To see or not to see: the case of the blind cavefish, Astyanax}

A dramatic case of evolution is presented by the cavefish variant of the Mexican river fish, Astyanax mexicanus. The cave variants differ sufficiently from the surface form to have initially been considered a distinct genus, Anoptichthys. One major difference between the cave and the surface forms is the lack of eyes, and of pigmentation. Based on QTL analysis, there seems to have been natural selection for eye loss, although melanophore loss seems mostly due to genetic drift rather than to selection (Protas et al., 2007). The question, then, is to determine what was the adaptive value of eye loss in the cave forms. Plausible selective schemes have been proposed, based primarily on energetic considerations: it would cost a lot to develop an eye when there is no more use of it, and thus selection would have favored the disappearance of eye development (or of pigmentation). This handy explanation lacks experimental support, however, as is the case for most of these a posteriori interpretations.

Some of the fishes that fell into caves (or wandered in and were unable to find their way out) necessarily survived, since they gave rise to the present cave populations. These fishes, and their progeny, presumably adapted to their new environment rather quickly, least the small surviving populations be quickly swept away. One may therefore expect that darkness-raised fish would somehow improve their survival rate in these new (and harsh) conditions over a few generations. If this is the case, then assessing the nature of these early changes may be experimentally feasible, and would give clear indication as to whether the basis for adaptive change is neural, or other.

The differences between surface and cave forms of Astyanax have been carefully studied over the past few years by W. Jeffery, T. Burt de Perera, and collaborators. They found that, besides the obvious morphological differences, important behavioral differences are also present between surface and cave forms. Surface fish tend to shoal but cave ones do not (Gregson and Burt de Perera, 2007). Further, the time devoted to inactivity (sleeping) is reduced in eyeless fish (Duboué etal., 2011), as is intra-specific aggressivity (Burchards et al., 1985). The feeding posture also differs between the two forms, and the cave form has evolved a new behavior dubbed VAB for Vibration Attraction Behavior (Yoshizawa et al., 2010). Not all of these differences have been studied in detail, yet the analysis of three of them has led to interesting results that are highly relevant to the present context.

\section{Orientational strategy in eyed and blind Astyanax}

Among the remarkable behavioral features of the cave fish is their ability to recognize small textural changes in their surroundings (Hassan, 1989), or to build and memorize extensive 3D-maps of their environment (Burt de Perera, 2014a). These achievements are based mostly or exclusively on information provided by the lateral line system, an information that is exclusively short-range, in striking contrast to visual information. In an attempt to determine to what extent the orientational strategy of fish is determined by the sensory modalities that they rely upon, or by "some underlying neural constraint", Sutherland et al. (2009) have examined to what extent the difference in sensory modalities between eyed and blind forms of Astyanax affect the way they orient through space. Using a simple T-maze with local landmarks differentiating the two arms, they found that both forms rely on the landmarks to find their goal, as opposed to using an egocentric mechanism such as "turn left, or right". Thus the blind form has learned to weave the short-range imaging of the landmarks into their internal long-range representation of their environment, as efficiently as the eyed form uses its long-range vision of the landmarks.

There is a difference between the two forms, however: unexpectedly, the seeing form shows an initial egocentric response which is later corrected by the visual cues, whereas the blind form shows no such initial bias. Thus, consistency between egocentric and landmark-based orientation may be more important for the blind fish than for the eyed form; yet the major difference between short-range (lateral line) and long-range (visual) sensory systems seems to have little impact on the role of landmark-based orientation strategies in this species. As the authors suggest, this conclusion is consistent with the idea that behavior is more constrained by its neural basis, than by sensory inputs.

Sutherland et al. also noted that, in spite of increased trajectory length when presented with conflicting egocentric and landmark cues, the blind fish showed no increase in the time needed to reach the rewarded end of the maze, suggesting that the fish swam faster. This is consistent with the observation that cave fish swim faster upon being faced with new landmarks (Teyke, 1988). Because blind fish identify new objects as distortions of the flow field generated by their own swimming and detected by their lateral line system, an increase in this flow field due to faster swimming will improve their analytical capabilities. Faster swimming is thereforea behavioral response that is likely to improve the detection of novel landmark features (Burt de Perera, 2014b). Thus cave fish have developed a new behaviour to improve the sensory capabilities of their lateral-line system, independent of any change in the sensory system itself, and they take advantage of this new behaviour both to identify new landmarks, to assess changes in the pattern of known landmarks, and to build long-distance spatial maps of their surroundings (Burt de Perera, 2014a).

\section{Feeding postures in surface vs. cave fish, and their genetic bases}

There is a marked difference in feeding posture between eyed and blind populations, with surface fish having a steeper angle than blind fish when feeding in complete darkness (Kowalko et al., 2013). Using two independently derived blind populations, the authors generated F2 hybrids to determine whether there is a correlation between feeding posture and various potentially relevant aspects of fish morphology such as jaw angle and width, number of maxillary teeth, number of taste buds, or orbit size, depth of head and body, all of which were found to differ between surface and at least some of the cave forms. They observed no significant correlation between any of these anatomical features, and feeding angle, among the F2 segregants. The authors propose that the convergent change in feeding posture in diverse cave populations likely evolved through changes in the nervous system itself. Since cave fish are better at finding food in the dark than surface fish, selection seems to have acted directly on neural circuitry to improve 
adaptation to the special conditions of cave life.

In the same experiment, the authors also performed QTLmapping which indicated that the convergent behavioral change in feeding posture has been achieved through at least partially independent mechanisms in the two cave populations, suggesting that cave fish have used whatever combination of alleles was available to them to shape their nervous system in a way that best fits their changed environment.

\section{Eye loss and the vibration attraction behavior (VAB)}

A third behavioral novelty observed in cave populations of Astyanax is a new prey-detection behavior that was nicknamed VAB for Vibration Attraction Behavior (Yoshizawa et al., 2010). These authors later found that the VAB phenotype is largely mediated by the additional neuromasts that form within the skin patch that covers the abortive eye (Yoshizawa et al., 2013). The extreme reduction in eye size in the cave forms is accompanied by an expansion of surrounding skin tissue, and by a corresponding expansion of the supra- and infra-orbital sections of the anterior lateral line system (Teyke, 1990). Interestingly, a VAB phenotype can occasionally be observed in surface populations, although in a very small proportion of the fish, and with lesser sensitivity. The question, then, is: what exactly happened to surface fish when plunged in complete darkness? Assuming some of them survived because they were fortunate enough to have some level of VAB behaviour, what evolved first: an increased capability to use this response for feeding, or an increased sensory input to amplify this response?

Assessing whether the remarkable development of VAB in blind fish precedes, or follows, the development of eyelid-neuromasts, might give us a clue to the essential question of what are the earliest steps of adaptation: morphological, or neural? This question could (and should) of course be examined in Astyanax, through surgical removal of the eye over a few generations - although this is a rather work-intensive and physiologically intrusive approach. Maybe a better way would be to make constitutively eyeless (ey) mutants, if at all feasible.

\section{Eye loss and central connectivity}

Eye loss in Astyanax is not mediated by any major alteration in eye forming genes such as eyeless, but rather, is achieved through a number of seemingly independent eye-degenerating processes (Wilkens and Strecker, 2003, Jeffery, 2009), in particular lens degeneration and retinal degeneration, as already suggested by earlier genetic studies (Sadoglu, 1975). Different cave populations have reached eye reduction through partially different genetic changes, such that a cross between independently derived cave populations usually yields hybrids with larger eyes than the parental forms and partially restored vision (Borowsky, 2008). These results are entirely consistent with the results of QTL analyses reported above, and strongly suggest that eye disappearance has been independently achieved in different cases through the selection of particular subsets of alleles among the species' polymorphism. What, then, could be the selective pressure that led independent cave populations to achieve eye loss through various means? Besides the possibility that eye loss improves survival through its indirect effect on eyelid neuromasts, another effect of blindness is that the massive reduction in eyes is most likely accompanied by a decrease in the eye projection to the optic tectum. This would allow some of the processing capability of the tectum to be diverted to the analysis of lateral line information. This would be similar to the process whereby part of the visual cortex is diverted to the analysis of somatosensory information, in congenitally blind humans (Sadato et al., 1996).

It is known that the primary projection of lateral line organs extends along the hindbrain, where second-order neurons project to several more anterior regions of the CNS, most prominently to a midbrain structure called torus semicircularis, homologous to the inferior colliculus of mammals. The torus itself projects massively to deep layers of the midbrain tectum, the major target of the eye projection. It has been reported in zebrafish, that the massive projection from torus to tectum found in all adult fishes is preceded early in larval life by the projection of a very small number of second-order neurons, directly from the hindbrain to deep layers of the tectum (Fame et al., 2006). It might be interesting to see to what extent the size of this early projection, and the dynamics of the later torus-tectum projection, differ in blind and eyed Astyanax.

If there is a change in the early or late representation of lateral line information in the tectum of blind fish, it might be illuminating to see if, and how quickly, blinding either surface Astyanax or zebrafish, leads to a change in this connectivity pattern. Of course, this would be neural adaptation to loss of a sense, yet it may give precious insights about how the nervous system copes with new environments - and, eventually, with new morphologies.

\section{Conclusion: assessing the dynamics of neural evolution}

We have argued that Astyanax may provide an excellent system to determine the relative importance of morphological and behavioral changes during the earliest steps of adaptation to new life conditions. A reasonable alternative might be to use the zebrafish, for which powerful genetic and molecular tools are available. Although some work has been done on raising embryos and early larvae in complete darkness (e.g. Bilotta, 2000), there is no published work on raising fish in complete darkness for long periods. Of course raising zebrafish under complete darkness, yet feeding them and caring for them properly, is very cumbersome. The obvious alternative would be to generate an eyeless line and use it for the purpose of evaluating to what extent, and how quickly, would a blind form adapt to its new phenotype.

More generally it seems that, with all we know about developmental genetics, it should be possible to challenge a given, genetically amenable species, with a morphological innovation, possibly based on features observed in related species, and see how quickly, and through which mechanism, these modified animals will adjust to this novelty to make it functional, and integrate it in their behavioral repertoire. Once we know that, then it may become possible to be more accurate in assigning relative roles to the processes of developmental innovation, of natural selection, and of adaptation, in evolution.

\section{Acknowledgements}

We thank L. Held for judicious comments on this paper and W. Jeffery for clarifications. We also thank our many colleagues for input to our thoughts, in particular E.B. Lewis, A. Garcia-Bellido and M. Bate, as well as INSERM (Institut National de la Santé et de la Recherche Médicale, France) and FNRS (Fonds National de la Recherche Scientifique, Belgium) for unfailing 
support. We are grateful to J. Arechaga for providing us with the opportunity to publish this essay, which will be our last paper, largely inspired from 40 years or so of studying the genetic bases of sensory neural development.

\section{References}

BADYAEV, A.V. (2009). Evolutionary significance of phenotypic accomodation in novel environments: an empirical test of the Baldwin effect. Phil Trans $R$ Soc $B$ 364: 1125-1141.

BILOTTA, J. (2000). Effects of abnormal lighting on the development of zebrafish visual behavior. Behav Brain Res. 116: 81-87.

BOROWSKY, R. (2008). Restoring sight in blind cavefish. Curr Biol 18: R23-R24.

BROWN GOODE, G. (1884) The Fisheries and Fishery Industry of the United States. Washington Government Printing Office, Washington, D.C.

BRUNET, J.F. and GHYSEN, A. (1999). Deconstructing cell determination: proneural genes and neuronal identity. BioEssays 21: 313-318.

BURCHARDS, H., DOLLE, A. and PARZEFALL, J.(1985). Aggressive behavior of an epigean population of Astyanax mexicanus (Characidae, Pisces) and some observations of three subterranean populations. Behav Processes 11: 222-235.

BURT DE PERERA, T. (2014a). Spatial parameters encoded in the spatial map of the blind Mexican cavefish, Astyanax fasciatus. Animal Behav., 68: 291-295.

BURT DE PERERA, T. (2014b). Fish can encode order in their spatial map. Proc $R$ Soc $B 271: 2131-2134$.

CANDE, J., ANDOLFATTO, P, PRUD'HOMME, B. STERN, D.L. and GOMPEL, N. (2012). Evolution of multiple additive loci caused divergence between Drosophila yakubaand $D$. santomeain wing rowing during male courtship. PLoSOne7:e43888.

CANDE, J., PRUD'HOMME, B. and GOMPEL, N. (2013) Smells like evolution: the role of chemoreceptor evolution in behavioral change. Curr Opin Neurobio/23: 152-158.

CANDE, J., STERN, D.L., MORITA, T., PRUD'HOMME, B. and GOMPEL, N. (2014). Looking under the lamp post: neither fruitless nor doublesex has evolved to generate divergent male courtship in Drosophila. Cell Rep. 8: 363-870.

CARROLL, S.B, PRUD'HOMME, B. and GOMPEL, N. (2008). Regulating evolution. Sci Am 298: 60-67.

CHITNIS, A.B, NOGARE, D.D. and MATSUDA, M. (2012). Building the posterior lateral line system in zebrafish. Dev. Neurobiol 72: 234-255.

CRISPO, E. (2007). The Baldwin effect and genetic assimilation: revisiting two mechanisms of evolutionary change mediated by phenotypic plasticity. Evolution 61: 2469-2479.

DIJKGRAAF, S. 1963. The functioning and significance of the lateral line organs. Biol Rev 38: 51-105.

DUBOUE E.R., KEENE, A.C. and BOROWSKY, R. (2011). Evolutionary convergence on sleep loss in cavefish populations. Curr Biol 21: 671-676.

ENGESZER, R.E., PATTERSON, L.B., RAO, A.A. and PARICHY, D.M. (2007). Zebrafish in the wild: a review of natural history and new notes from the field. Zebrafish 4: 21-40.

FAME, R.M., BRAJON, C. and GHYSEN, A. (2006). Second-order projection from the posterior lateral line in the early zebrafish brain. Neural Dev 1: 4.

GHYSEN, A. and DAMBLY-CHAUDIERE, C. (2007). The lateral line microcosmos. Genes Dev 21: 2118-2130.

GHYSEN, A., SCHUSTER, K., COVES, D., DELAGANDARA, F., PAPANDROULAKIS, N. and ORTEGA, A. (2010). Development of the posterior lateral line system in Thunnus thynnus, the Atlantic blue-fin tuna, and in its close relative Sarda sarda. Int J Dev Biol 54: 1317-1322.

GHYSEN, A., DAMBLY-CHAUDIERE, C., COVES, D., DE LA GANDARA, F. and ORTEGA, A. (2012). Developmental origin of a major difference in sensory patterning between zebrafish and bluefin tuna. Evol Dev 14: 204-211.

GHYSEN, A., WADA, H. andDAMBLY-CHAUDIERE, C. (2014). Patterning the posterior lateral line in teleosts: evolution of development. In Flow Sensing in air and water (Eds H Bleckman, J Mogdans J and SL Coombs). Springer Verlag, pp 295-318.

GOULD, S.J. (1989). Wonderful life: The Burgess shale and the nature of history. WW Norton \& Co., New York.

GOULD, S.J. and LEWONTIN, R.C. (1979). The spandrels of San Marco and the Panglossian paradigm: a critique of the adaptationist programme. Proc. Roy. Soc. Lond. B 205: 581-98.
GRANT, K.A., RAIBLE, D.W. and PIOTROWSKI, T. (2005). Regulation of latent sensory hair cell precursors by glia in the zebrafish lateral line. Neuron 45: 69-80.

GREGSON, J.N.S. and BURT DE PERERA, T. (2007). Shoaling in eyed and blind morphs of the characin Astyanax fasciatus under light and dark conditions. $J$ Fish Biol 70: 1615-1619.

HARRISON, R.G. (1904). Experimentelle Untersuchungen über die Entwicklung der Sinnesorgane der Seitenlinie bei den Amphibian. Arch Mikrosk Anat 63: 35-149.

HASSAN, E.S. 1989. Hydrodynamic imaging of the surroundings by the lateral of the blind cavefish Anoptichtys jordani. In The mechanosensory lateral line: neurobiology and evolution (Eds S Combs S, P Görner and H Münz). Springer, New York, pp 217-228.

HURLEY, I.A., MUELLER, R.L., DUNN, K.A., SCHMIDT EJ, FRIEDMAN, M., HO, R.K., PRINCE, V.E., YANG, Z., THOMAS, M.G. and Coates, M. (2007). A new time-scale for ray-finned fish evolution. Proc $R$ Soc B 274: 489-498.

JEFFERY, W.R. (2009). Regressive evolution in Astyanax cavefish. Annu Rev Genet 43: 25-47.

KOWALKO, J.E., ROHNER, N., LINDEN, T.A., ROMPANI, S.B., WARREN, W.C., BOROWSKY, R., TABIN, C.J., JEFFERY, W.R. and YOSHIZAWA, M. (2013). Convergence in feeding posture occurs through different genetic loci in independently evolved cave populations of Astyanax mexicanus. Proc Nat Acad USA 110: 16933-16938.

LEDENT, V. (2002). Postembryonic development of the posterior lateral line in zebrafish. Development 129: 597-604.

LEWIS, E.B. (1978). A gene complex controlling segmentation in Drosophila. Nature 276: 565-570.

LOPEZ-SCHIER, H. and HUDSPETH, A.J. (2005). Supernumerary neuromasts in the posterior lateral line of zebrafish lacking peripheral glia. Proc Natl Acad Sci USA 102: 1496-1501.

MA, E.Y. and RAIBLE, D.W. (2009). Signaling pathways regulating zebrafish lateral line development. Curr Biol 19: R381-386.

MABEE, P.M., CROTWELL, P.L., BIRD, N.C. and BURKE, A.C. (2002). Evolution of median fin modules in the axial skeleton of fishes. J Exp Zool 294: 77-90.

METCALFE, W.K. (1989). In The mechanosensory lateral line: neurobiology and evoIution. (Eds S Coombs, P Görner and H Münz). Springer, New York, pp 147-159.

MONTGOMERY, J., COOMBS, S. and JANSSEN, J. (1994). Form and function relationships in lateral line systems: comparative data from six species of Antarctic notothenioid fish. Brain Behav Evol 44: 299-306.

MONTGOMERY, J., COOMBS, S. and HALSTEAD, M. (1995). Biology of the lateral line in fishes. Rev Fish Biol Fisheries 5: 399-416.

NELSON, J.S. (1994). Fishes of the world. John Wiley \& Sons, New York.

NORTHCUTT, R.G. (1990). Ontogeny and phylogeny: a re-evaluation of conceptual relationships and some applications. Brain Behav Evol 36: 116-140.

NUNEZ, V.A., SARRAZIN, A.F., CUBEDO, N., ALLENDE, M.L., DAMBLY-CHAUDIERE, C. and GHYSEN, A. (2009). Postembryonic development of the posterior lateral line in the zebrafish. Evol Dev 11: 391-404.

PICHON, F. and GHYSEN, A. (2004). Evolution of posterior lateral line development in fish and amphibians. Evol Dev 3: 187-193.

PROTAS, M., CONRAD, M., GROSS, J.B., TABIN, C. and BOROWSKY, R. (2007). Regressive evolution in the Mexican cave tetra, Astyanax mexicanus. Curr Biol 17: $452-454$

SADATO, N., PASCUAL-LEONE, A., GRAFMAN, J., IBANEZ, V., DEIBER, M.P., DOLD, G. and HALLETT, M. (1996). Activation of the primary visual cortex in blind subjects. Nature 380: 526-528.

SADOGLU, P. (1975). Genetic Paths Leading to Blindness in Astyanax Mexicanus. In: NATOAdvanced Study Institutes Series Volume 1, Springer, New York, pp 419-426.

SAPEDE, D., GOMPEL, N., DAMBLY-CHAUDIERE, C. and GHYSEN, A. (2002). Cell migration in the postembryonic development of the fish lateral line. Development 129: 605-615.

SIMPSON, P. and MARCELLINI, S. (2006). The origin and evolution of stereotyped patterns of macrochaetes on the nota of cyclorraphous Diptera. Heredity I 97: 148-156.

SPENCE, R., GERLACH, G., LAWRENCE, C. and Smith, C.H. (2008). The behaviour and ecology of the zebrafish, Danio rerio. Biol Rev Camb Philos Soc 18: 13-34. STEINKE, D., SALZBURGER, W. and MEYER, A. (2006). Novel relationships among 


\section{A. Ghysen and C. Dambly-Chaudière}

ten fish model species revealed based on a phylogenomic analysis using ESTs. J Mol Evol 62: 772-784.

STONE, L.S. (1933). The development of lateral line sense organs in amphibians observed in living and vital-stained preparations. J Comp Neur 57: 507-540.

SUTHERLAND, L., HOLBROOK, R. and BURT DE PERERA T. (2009). Sensory system affects orientational strategy in a short-range spatial task in blind and eyed morphs of the fish, Astyanax fasciatus. Ethology 115: 504-510

SZNAJDER B., SABELIS, M.W. and EGAS, M. (2012). How adaptive learning affects evolution: reviewing theory of the Baldwin effect. Evol Biol 39: 301-310.

TEYKE, T. (1988). Flow field, swimming velocity and boundary layer: parameters which affect the stimulus for the lateral line organ in blind fish. J Comp Physiol A 163, 53-61

TEYKE, T. (1990). Morphological differences in neuromasts of the blind cave fish Astyanax hubbsi and the sighted river fish Astyanax mexicanus. Brain Behav Evol 35: 23-30.

WADA, H., DAMBLY-CHAUDIERE, C., KAWAKAMI, K. and GHYSEN, A. (2013). Innervation is required for sense organ development in the lateral line system of adult zebrafish. Proc Natl Acad Sci USA 110: 5659-5664.

WADA, H., IWASAKI, M. and KAWAKAMI, K. (2014). Development of the lateral line canal system through a bone remodeling process in zebrafish. Dev Biol392: 1-14

WEBB, J.F. (1989). Gross morphology and evolution of the mechanoreceptive latera line system in teleost fishes. Brain Behav Evol 33: 205-222.

WEIHS, D. (1973). The mechanism of rapid starting of slender fish. Biorheology 10: $343-350$

WEST-EBERHARD M.J. (2003). Developmental Plasticity and Evolution. Oxford Univ. Pr., New York.

WILKENS, H. and STRECKER, U. (2003). Convergent evolution of the cavefish Astyanax (Characidae, Teleostei): genetic evidence from reduced eye-size and pigmentation. Biol J Linnean Soc 80: 545-554

WOHL, S. and SCHUSTER, S. (2007). The predictive start of hunting archer fish: a flexible and precise motor pattern performed with the kinematics of an escape C-start. J Exp Biol 210: 311-324.

YOSHIZAWA, M., GORICKI, S., SOARES, D. and JEFFERY, W.R. (2010) Evolution of a behavioral shift mediated by superficial neuromasts helps cavefish find food in darkness. Curr Biol 20: 1631-1636.

YOSHIZAWA, M., O'QUINN, K.E. and JEFFERY, W.R. (2013). Evolution of an adaptive behavior and its sensory receptors promotes eye regression in blind cavefish: response to Borowsky. BMC Biol 11: 82. 


\section{Further Related Reading, published previously in the Int. J. Dev. Biol.}

Patterning the nervous system through development and evolution

Alain Ghysen, Christine Dambly-Chaudière and David W. Raible

Int. J. Dev. Biol. (2010) 54: S1-S14

http://www.intjdevbiol.com/web/paper/103182ag

Patterning and cell fate in ear development

Berta Alsina, Fernando Giraldez and Cristina Pujades

Int. J. Dev. Biol. (2009) 53: 1503-1513

http://www.intjdevbiol.com/web/paper/072422ba

The molecular biology of ear development - "Twenty years are nothing"

Fernando Giraldez and Bernd Fritzsch

Int. J. Dev. Biol. (2007) 51: 429-438

http://www.intjdevbiol.com/web/paper/072390fg

The origin and evolution of the nervous system

Alain Ghysen

Int. J. Dev. Biol. (2003) 47: 555-562

http://www.intjdevbiol.com/web/paper/14756331

The developmental biology of neural connectivity

Alain Ghysen

Int. J. Dev. Biol. (1992) 36: 47-58

http://www.intjdevbiol.com/web/paper/1627474

5 yr ISI Impact Factor $(2013)=2.879$

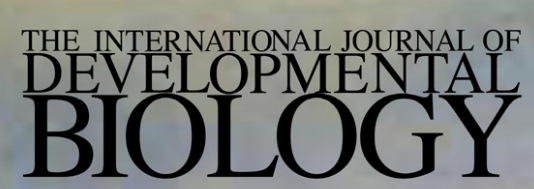

Volume 47 Nos. $7 / 8$ Special Issue

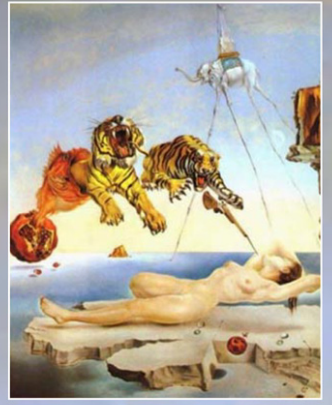

Evolution \& Development
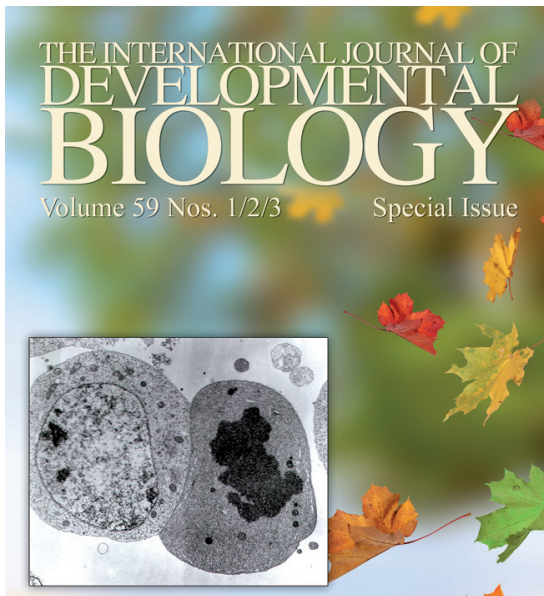

Cell Death in Development \& Tumo

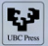

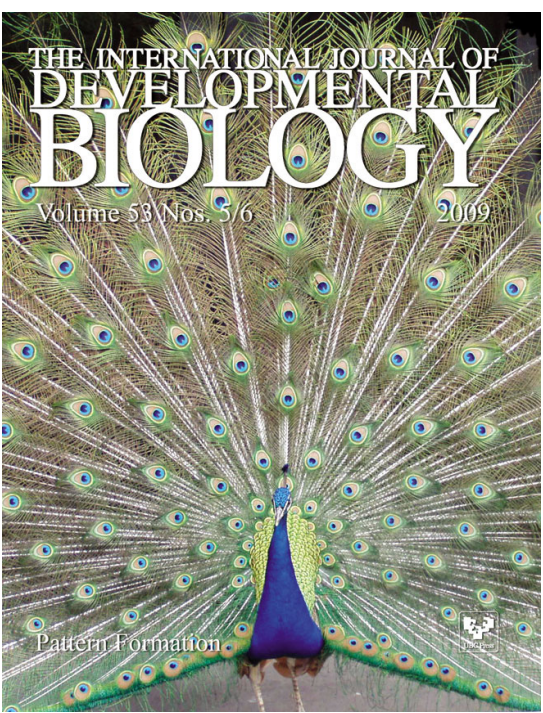

THE INTERNATIONAL JOURNAL OF DEVEIOPNENTAI

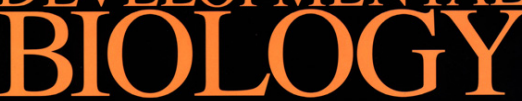

Volume 42 No. 3

Special issue

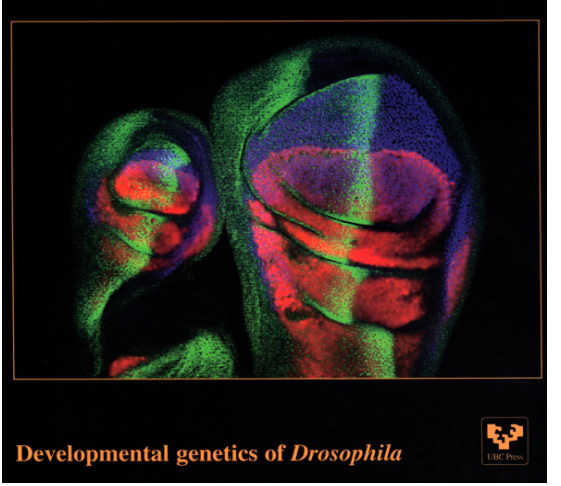

